\title{
Chronic productive cough in young adults is very often due to chronic rhino-sinusitis
}

\author{
A.G. Corsico1, S. Villani2, M.C. Zoia1, R. Niniano1, E. Ansaldo1, \\ G. Cervio1, P.M. Quaresima1, E. Gatto1, E. Crippa1, A. Marinoni2, \\ A. Foresi 3 , E. Pozzi ${ }^{1}$, I. Cerveri 1
}

ABSTRACT: Chronic productive cough in young adults is very often due to chronic rhino-sinusitis. A.G. Corsico, S. Villani, M.C. Zoia, R. Niniano, E. Ansaldo, G. Cervio, P.M. Quaresima, E. Gatto, E. Crippa, A. Marinoni, A. Foresi, E. Pozzi, I. Cerveri.

Background. Chronic productive cough is a common clinical problem; often potential causes outside the lower respiratory tract are forgotten or ignored. The aim of this study was to make a precise etiopathogenetic diagnosis of chronic productive cough in young adults.

Methods. In a clinical setting, 212 subjects (mean age $41 \pm 5$ years) who had reported chronic productive cough in a previous postal survey of a young adult population underwent within two years clinical and functional investigations following a rational diagnostic approach. Two pulmonologists independently established the diagnosis using a clinically structured interview on nasal and respiratory symptoms, spirometry and other tests when appropriate (bronchodilator test or methacholine bronchial challenge, chest radiography); if rhino-sinusitis was suspected, subjects underwent an ENT examination with nasal endoscopy and/or sinus computed tomography.

Results. At the end of the diagnostic procedure, 87 subjects $(41 \%)$ no longer had chronic productive cough and had normal function. Fifty-eight subjects $(27 \%)$ had chronic rhino-sinusitis; seventeen subjects $(8 \%)$ had asthma, and of these fourteen also had chronic rhino-sinusitis; 50 subjects $(24 \%)$ had COPD stage $0+$, of these seven also had chronic rhino-sinusitis. Chronic rhino-sinusitis was more frequent in females than in males $(p<0.05)$.

Conclusions. Both in clinical practice and in epidemiological studies, it is important to consider that the origin of chronic productive cough could be frequently outside the lower respiratory tract; a consistent percentage of young adults with persistent productive cough has indeed chronic rhino-sinusitis.

Monaldi Arch Chest Dis 2007; 67: 2, 90-94.

Keywords: Smoking, rhino-sinusitis, chronic obstructive pulmonary disease, asthma.

${ }_{1}^{1}$ Division of Respiratory Diseases, IRCCS Policlinico San Matteo, University of Pavia,

2 Department of Health Applied Science, University of Pavia,

3 Respiratory Pathophysiology Unit, Sesto San Giovanni Hospital, Sesto San Giovanni (MI), Italy.

This work was partially supported by grants from the Italian Ministry of Education, University and Research; GlaxoSmithKline Italia; the National Health Service, ASL Pavia; IRCCS Policlinico San Matteo, Pavia; and the Province of Pavia.

Correspondence: Dr. Angelo Corsico, Clinica di Malattie dell'Apparato Respiratorio, IRCCS Policlinico San Matteo, Via Taramelli 5, 27100 Pavia, Italy; e-mail: angelo.corsico@unipv.it.

\section{Introduction}

The combination of chronic cough and phlegm poses a common diagnostic problem, being one of the most frequent complaints for which patients seek medical care from pulmonologists [1-3]. Community surveys suggested that the prevalence of a recurrent cough is up to $40 \%$ and that the prevalence of a persistent productive cough is as high as 10\% [4-6]. The recent multi-centre Italian Study of Asthma in Young Adults (ISAYA) carried out between 1998-2000 confirmed a startlingly high prevalence of chronic productive cough [7]. The Chronic Obstructive Pulmonary Disease (COPD) staging system of the Global Initiative for Chronic Obstructive Lung Disease (GOLD), reinforced in the American Thoracic Society (ATS) /
European Respiratory Society (ERS) Task Force guidelines, introduced the presence of chronic cough and/or sputum production in the absence of airflow obstruction as an indicator for identifying subjects at risk of developing COPD later in life $[8,9]$. However, the few prospective studies aimed at verifying the predictive value for COPD of these chronic symptoms gave contrasting results [10, 11]. Chronic respiratory symptoms in many subjects may remit, as documented in the Copenhagen City Heart Study [10], or may be attributable, at least in part, to other diseases sharing the same symptoms but differing from COPD in their pathogenesis, treatment and evolution, such as chronic rhino-sinusitis or asthma [12-14]. The combination of chronic cough and phlegm very often has been associated with upper airway disease [15]; 
however, objective verification of this association is frequently lacking. Many reported series, mainly from the USA, indicate that post-nasal drip syndrome is one of the most common causes of a chronic productive cough [16, 17].

The aim of this study was to make a precise diagnosis of the causes of chronic productive cough in a large group of young adults. For this purpose, all the subjects who had reported having a chronic cough and phlegm in a previous postal survey on a young adult population in Italy were invited to undergo clinical and functional investigations of their symptoms using a rational diagnostic approach.

\section{Methods}

\section{Subjects}

The previous cross-sectional survey of the young adult population was carried out between 1998 and 2000 in nine Italian centres (ISAYA) [18]. In each centre a random sample of about 3000 people aged 20-44 years was chosen; there were more than 25,000 eligible subjects and the overall response rate to the screening questionnaire was $72 \%$. This survey, although specifically aimed at evaluating the prevalence of asthma, provided the present authors with the opportunity of assessing the prevalence of subjects with self-reported chronic productive cough in young age classes. The self-administered questionnaire used contained validated questions on symptoms and risk factors for asthma and COPD, mostly taken from the European Community Respiratory Health Survey (ECRHS) questionnaire [19].

Only the subjects living in one of the centres (Pavia, northern Italy) were asked to participate in this specific study. The question on the postal questionnaire that was used to select subjects was "Have you had cough and phlegm on most days for as much as three months per year and for at least two successive years?" The target sample was constituted by 262 subjects, smokers and nonsmokers, who gave a positive response to this question. Ethics approval for the study was obtained from the competent Ethical Committee; all patients gave informed written consent.

\section{Study Design}

The clinical and functional studies were completed within two years after the postal survey. At clinical examination, two pulmonologists (AG. C. and MC. Z.), independently, had to establish a diagnosis following a rational approach adapted from Irwin and Madison [13]. This approach started in all subjects with a structured interview containing detailed questions on symptoms of asthma, rhinitis, COPD and their known risk factors according to the ECRHS protocol [www.ecrhs.org] [20]. In addition, the subjects were asked about the presence of anterior rhinorrhoea, nasal obstruction, sinus pain, sneezing, nasal itch, post-nasal drip, and hyposmia/anosmia, as described in the 1996 Rhino-sinusitis Task Force Report [21]. The two pulmonologists then examined the results of the spirometry examination and the measurement of lung volumes, assessed in all subjects. At that point, the physicians narrowed down the list of possible diagnoses by reviewing the patient's history and physical examination and focusing on the most common causes of chronic productive cough. If rhino-sinusitis was clinically suspected, subjects underwent an Ear, Nose and Throat (ENT) examination with nasal endoscopy and/or sinus computed tomography [22].

When subjects presented other atypical features or when an agreement was not reached by the two specialists, other useful investigations, such as chest radiography, a bronchodilator test or methacholine bronchial challenge, could be requested.

All the clinical and functional information was processed based on GINA guidelines for asthma [23], the GOLD and ERS/ATS criteria for COPD (stage 0+) [8,24] and the Allergic Rhinitis and its Impact on Asthma (ARIA) guidelines for rhino-sinusitis [25].

\section{Measurements}

All measurements were performed by an investigator unaware of the responses to the questionnaires or information collected in the structured interview. Lung function tests, bronchodilator tests, and methacholine challenge were performed according to ECRHS protocols [20]. A Vmax 22 system and an Autobox V6200 (SensorMedics, Yorba Linda, CA) were used to measure lung function. Thoracic gas volumes were measured with the subjects seated in the body plethysmograph and panting against a closed shutter at a frequency slightly $<1 \mathrm{~Hz}$ with their cheeks supported. Total lung capacity (TLC) was calculated as the sum of thoracic gas volume and the inspiratory capacity measured soon after reopening the shutter; residual volume was calculated as the difference between TLC and a slow expiratory vital capacity. Airflow obstruction was defined as $\mathrm{FEV}_{1} / \mathrm{FVC}<0.70$ [8].

\section{Statistics}

Heterogeneity in the distribution of smoking habit between genders and in the distribution of the different diagnoses between genders and among smoking habits were compared using the Chisquare test. A $p$ value of $<0.05$ was considered statistically significant. All tests were two tailed (statistical software Stata 7, Statacorp, College Station, TX, USA). Data is presented as means \pm SD.

\section{Results}

Out of the 262 subjects who had given a positive response to the aforementioned question on chronic productive cough in the postal survey conducted between 1998 and 2000, 212 subjects (107 males and 105 females, mean age $41 \pm 5$ years) participated in this clinical and functional study (response rate: $81 \%$ ). 
One hundred and fourteen subjects (54\%) were current smokers, 38 subjects $(18 \%)$ were past smokers and $60(28 \%)$ were non-smokers. The distribution of smoking habit was significantly different between genders $(p<0.001)$, with non-smokers being more frequently females than males $(73 \%$ vs $27 \%)$.

In 172 subjects (81\%) the two pulmonologists agreed on the diagnosis on the basis of the clinical interview, lung function data, and ENT examination without other tests. Thirty-six subjects underwent a methacholine challenge and four subjects with airflow obstruction underwent a bronchodilator test.

At the end of the diagnostic procedure, a group of 87 subjects $(41 \%)$ no longer had chronic respiratory symptoms and had normal lung function. 58 subjects $(27 \%)$ were diagnosed as having chronic rhino-sinusitis. Seventeen subjects $(8 \%)$ were found to have asthma: fourteen of these subjects also had chronic rhino-sinusitis. Finally, 50 subjects $(24 \%)$ had COPD stage $0+$; seven of these subjects also had chronic rhino-sinusitis and three had airflow obstruction suggesting a COPD stage 1 (figure 1).

Among the 87 subjects with normal lung function and no longer reporting chronic respiratory symptoms, six had stopped smoking and eight had received therapy from their general practitioner in the interval between the mail questionnaire and the clinical and functional study. The distribution of the different diagnoses was significantly different between genders $(p<0.05)$ and among smoking habits $(p<0.0001)$. In fact, the percentage of subjects with COPD stage 0+ was higher in males than in females while that of subjects with rhinosinusitis was higher in females than in males (table 1). The percentage of subjects with COPD stage 0+ was higher in current smokers than in past or nonsmokers while the percentage of subjects with asthma was lower in current smokers than in past or non-smokers (table 2).

Lung function parameters according to the different diagnosis are reported in table 3; betweengroup comparisons are not given because lung function parameters were used for the diagnosis.

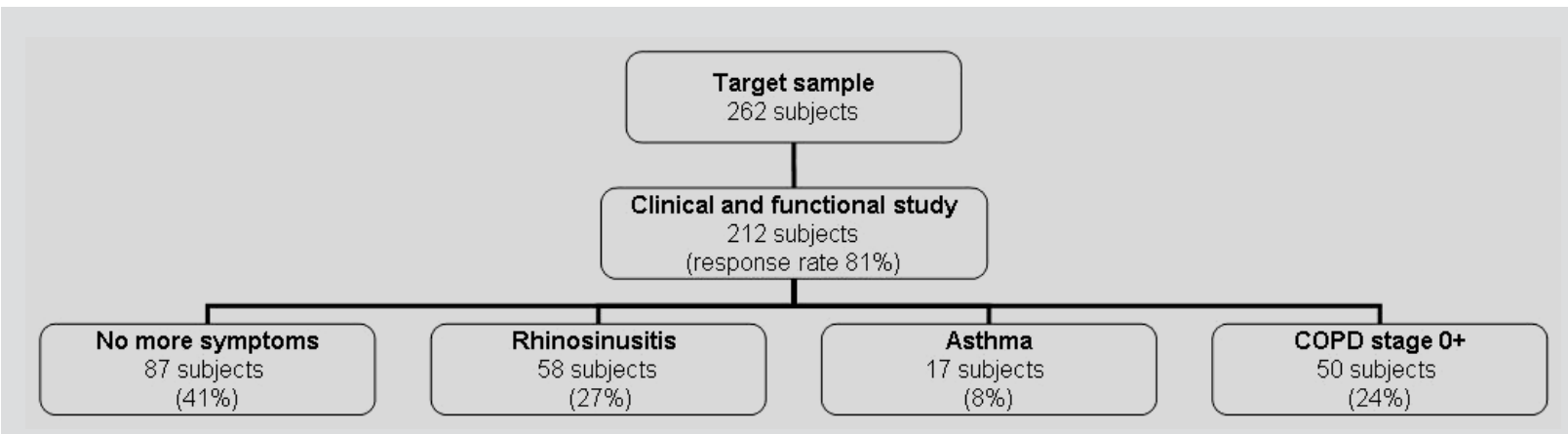

Fig. 1. - Flow chart of subjects participating in the clinical and functional study from the 262 subjects with chronic cough and the phlegm identified in the postal survey to the final diagnosis.

Table 1. - Distribution of clinical diagnoses by gender*

\begin{tabular}{lcr}
\hline & $\begin{array}{c}\text { Males } \\
(\mathbf{N}=107)\end{array}$ & $\begin{array}{c}\text { Females } \\
(\mathbf{N}=\mathbf{1 0 5})\end{array}$ \\
\hline No more symptoms & $42(39 \%)$ & $45(43 \%)$ \\
COPD stage 0+ & $33(31 \%)$ & $17(16 \%)$ \\
Asthma & $10(9 \%)$ & $7(7 \%)$ \\
Rhino-sinusitis & $22(21 \%)$ & $36(34 \%)$ \\
\hline
\end{tabular}

* Chi-square test, $p<0.05$.

Table 2. - Distribution of clinical diagnoses by smoking habit*

\begin{tabular}{lccc}
\hline & $\begin{array}{c}\text { Non-smokers } \\
(\mathbf{N = 6 0 )}\end{array}$ & $\begin{array}{c}\text { Past smokers } \\
\mathbf{( N = 3 8 )}\end{array}$ & $\begin{array}{c}\text { Smokers } \\
(\mathbf{N = 1 1 4})\end{array}$ \\
\hline No more symptoms & $27(45 \%)$ & $20(53 \%)$ & $40(35 \%)$ \\
COPD stage 0+ & $2(3 \%)$ & $2(5 \%)$ & $46(40 \%)$ \\
Asthma & $8(13 \%)$ & $4(11 \%)$ & $5(4 \%)$ \\
Rhino-sinusitis & $23(38 \%)$ & $12(32 \%)$ & $23(20 \%)$ \\
\hline * Chi-square test, $p<0.0001$. & & \\
\end{tabular}


Table 3. - Lung function by clinical diagnoses

\begin{tabular}{lcccc}
\hline & $\begin{array}{c}\text { No more symptoms } \\
(\mathbf{N = 8 7})\end{array}$ & $\begin{array}{c}\text { COPD stage 0+ } \\
(\mathbf{N = 5 0 )}\end{array}$ & $\begin{array}{c}\text { Asthma } \\
(\mathbf{N = 1 7})\end{array}$ & $\begin{array}{c}\text { Rhino-sinusitis } \\
(\mathbf{N}=\mathbf{5 8})\end{array}$ \\
\hline $\mathrm{FEV}_{1}$ (\% pred.) & $100 \pm 20$ & $88 \pm 18$ & $90 \pm 25$ & $97 \pm 19$ \\
$\mathrm{FEV}_{1}$ /FVC (\%) & $82 \pm 5$ & $79 \pm 6$ & $77 \pm 9$ & $83 \pm 8$ \\
$\mathrm{RV}$ (\% pred.) & $97 \pm 20$ & $104 \pm 16$ & $104 \pm 15$ & $98 \pm 18$ \\
\hline
\end{tabular}

Data is presented as means $\pm \mathrm{SD}$. Between-group comparisons are not given because lung function parameters were used for the diagnosis.

\section{Discussion}

Our study shows that a consistent percentage of young adults with persistent productive cough have chronic rhino-sinusitis whereas only about one in four subjects with chronic productive cough can reasonably be defined as at risk of COPD. In addition it confirms that chronic productive cough disappears spontaneously or after treatment in a large proportion of young adults within few years.

The association we found between chronic nasal symptoms and chronic productive cough confirms that the post-nasal drip is a frequent cause of cough, which could also contribute to the volume of sputum expectorated. The large proportion of our subjects reporting chronic productive cough who were clinically diagnosed as suffering only from chronic rhino-sinusitis suggests that this relationship may be, at least in part, due to some confusion by the patients in distinguishing between post-nasal drip and lower airway symptoms; the question on chronic productive cough in the questionnaire did not, by itself, allow subjects to discriminate between an upper or lower airway origin of their symptoms. In our study chronic rhino-sinusitis was also diagnosed in $15 \%$ of young adults with COPD stage 0 suggesting that postnasal drip may also contribute to lower respiratory tract symptoms. Roberts found a very high prevalence of nasal symptoms in patients with moderate to severe COPD, with about $40 \%$ of such patients having a post-nasal drip [26]. Although rhino-sinusitis and lower airway involvement are also frequently associated in the same patient, their interrelationship is still poorly understood [22]. Prospective studies should be undertaken to characterise the time course of the nasal symptoms in relation to the respiratory ones.

Persistent cough and sputum production often precede the development of airflow limitation and can, therefore, offer a unique opportunity to identify subjects at risk of COPD for an early intervention. However, while the importance of promoting the concept of an "at risk" population in a global health policy is well recognised, the appropriateness of stating that chronic productive cough is a marker of an ongoing pathological process in the lower airways has already been questioned by Vestbo and Lange who found, in a long-term follow-up study, that COPD stage 0 is not a stable feature and is of little help in predicting later development of COPD [10]. In fact, these authors retrospectively showed that about $40 \%$ of subjects who reported having chronic productive cough no longer had these symptoms after 5 years. In agreement with Vestbo's study, we found that $41 \%$ of young adults who reported chronic productive cough in a postal questionnaire no longer did so when evaluated in a clinical setting using a more detailed questionnaire administered by a physician after an interval of no longer than two years. This indicates that chronic productive cough is not always irreversible, even when it has been present for more than two years: in our subjects this may have been in part the consequence of smoking cessation and in part due to the fact that some of the subjects had sought medical care from pulmonologists. At the end of our diagnostic procedure, only about one in four subjects with chronic productive cough was defined as at risk of COPD and this small proportion of subjects may explain the lack of predictive value of chronic productive cough.

In the majority of cases routine tests were enough to solve the diagnostic problems. However, in the other cases useful information was added by methacholine bronchial challenge and bronchodilator test.

The strength of our study is that the sample constituted young adults from the general population. Studying those people referred to specialist cough clinics to seek medical advice would not have provided information of the same relevance. To overcome the limits of a subjective clinical approach to the diagnosis, a rational diagnostic pathway adapted from Irwin and Madison and similar to that recently proposed by Kastelik et al., was applied and two independent pulmonologists had to agree on the final diagnosis $[13,27]$.

In conclusion, it is important to be aware that the origin of chronic productive cough may lie outside the lower respiratory tract and of the interactions between the upper and lower airways. In epidemiological studies, it is important to consider that the positive response to chronic cough and phlegm, particularly in young adults, could be frequently due to chronic rhino-sinusitis. In clinical practice, the persistence of chronic respiratory symptoms such as chronic cough and phlegm, should be carefully investigated with a multidisciplinary approach. 


\section{References}

1. French CT, Fletcher KE, Irwin RS. Gender Differences in Health-Related Quality of Life in Patients Complaining of Chronic Cough. Chest 2004; 125; 482-488.

2. Morice AH, JA Kastelik. Cough 1: Chronic cough in adults. Thorax 2003; 58: 901-7.

3. Pavord ID. Chronic cough: a rational approach to investigation and management. Eur Respir J 2005; 25: 213-215.

4. Cullinan P. Persistent cough and sputum: prevalence and clinical characteristics in south east England. Respir Med 1992; 86: 143-149.

5. Janson C, Chinn S, Jarvis D, Burney P. Determinants of cough in young adults participating in the European Community Respiratory Health Survey. Eur Respir J 2001; 18: 647-654.

6. De Marco R, Accordini S, Cerveri I, et al. An international survey of chronic obstructive pulmonary disease in young adults according to GOLD stages. Thorax 2004; 59: 120-125.

7. Cerveri I, Accordini S, Corsico A, et al. Chronic cough and phlegm in young adults. Eur Respir $J$ 2003; 22: 413-417.

8. Global Initiative for Chronic Obstructive Lung Disease. Global Strategy for the Diagnosis, Management and Prevention of Chronic Obstructive Pulmonary Disease. NHLBI/WHO workshop report. Bethesda, National Heart, Lung and Blood Institute, April 2001; Update of the Management Sections, GOLD website (www.goldcopd.com). Updated: 2004

9. Celli BR, MacNee W, ATS/ERS Task Force. Standards for the diagnosis and treatment of patients with COPD: a summary of the ATS/ERS position paper. Eur Respir $J$ 2004; 23: 932-946.

10. Vestbo J, Lange P. Can GOLD Stage 0 provide information of prognostic value in chronic obstructive pulmonary disease? Am J Respir Crit Care Med 2002; 166: 329-332.

11. Lindberg A, Jonsson AC, Ronmark E, Lundgren R, Larsson LG, Lundback B.. Ten-year cumulative incidence of COPD and risk factors for incident disease in a symptomatic cohort. Chest 2005; 127: 1544-1552.

12. Palombini BC, Villanova CA, Araujo E, et al. A pathogenic triad in chronic cough: asthma, postnasal drip syndrome, and gastroesophageal reflux disease. Chest 1999; 116: 279-284.

13. Irwin SR, Madison JM. The diagnosis and treatment of cough. $N$ Engl J Med 2000; 343: 1715-1721.

14. Irwin RS, Baumann MH, Bolser DC, et al. American College of Chest Physicians (ACCP). Diagnosis and management of cough executive summary: ACCP evidence-based clinical practice guidelines. Chest 2006; 129 (1 Suppl): 1S-23S.

15. Bucca C, Rolla G, Brussino L, De Rose V, Bugiani M. Are asthma-like symptoms due to bronchial or extrathoracic airway dysfunction? Lancet 1995; 346: 791795.

16. Irwin RS, Curley FJ, French CL. Chronic cough. The spectrum and frequency of causes, key components of the diagnostic evaluation, and outcome of specific therapy. Am Rev Respir Dis 1990; 141: 640-647.

17. Smyrnios NA, Irwin RS, Curley FJ, French CL. From a prospective study of chronic cough: diagnostic and therapeutic aspects in older adults. Arch Intern Med 1998; 158: 1222-1228.

18. de Marco R, Locatelli F, Cerveri I, et al. Incidence and remission of asthma: a retrospective study on the natural history of asthma in Italy. J Allergy Clin Immunol 2002; 110: 228-235.

19. de Marco R, Zanolin ME, Accordini S, et al. A new questionnaire for the repeat of the first stage of the European Community Respiratory Health Survey: a pilot study. Eur Respir J 1999; 14: 1044-1048.

20. Burney PG, Luczynska C, Chinn S, Jarvis D. The European Community Respiratory Health Survey. Eur Respir J 1994; 7: 954-960.

21. Lanza DC, Kennedy DW. Adult rhino-sinusitis defined. Otolaryngol Head Neck Surg 1997; 117 (suppl 3): 1-7.

22. Fokkens W, Lund V, Bachert C, et al. EAACI Position Paper on Rhino-sinusitis and Nasal Polyps Executive Summary. Allergy 2005; 60: 583-601.

23. Global Initiative for Asthma. Global strategy for asthma management and prevention: NHLBI/WHO workshop report. Updated 2004. Bethesda, Md.: National Heart, Lung, and Blood Institute, 2004

24. American Thoracic Society (New York, USA) and European Respiratory Society (Lausanne Switzerland). Standards for Diagnosis and Management of patients with COPD. 2004. American Thoracic Society (ATS) and European Respiratory Society (ERS). http: //www.thoracic.org/copd/pdf/copddoc.pdf

25. Bousquet J, van Cauwenberge P, Khaltaev N. Allergic rhinitis and its impact on asthma. J Allergy Clin Immunol 2001; 108 (suppl 5): 147-334.

26. Roberts NJ, Lloyd-Owen SJ, Rapado F, at al. Relationship between chronic nasal and respiratory symptoms in patients with COPD. Respir Med 2003; 97: 909-914.

27. Kastelik JA, Aziz I, Ojoo JC, Thompson RH, Redington $\mathrm{AE}$, Morice $\mathrm{AH}$. Investigation and management of chronic cough using a probability-based algorithm. Eur Respir J 2005; 25: 235-243.

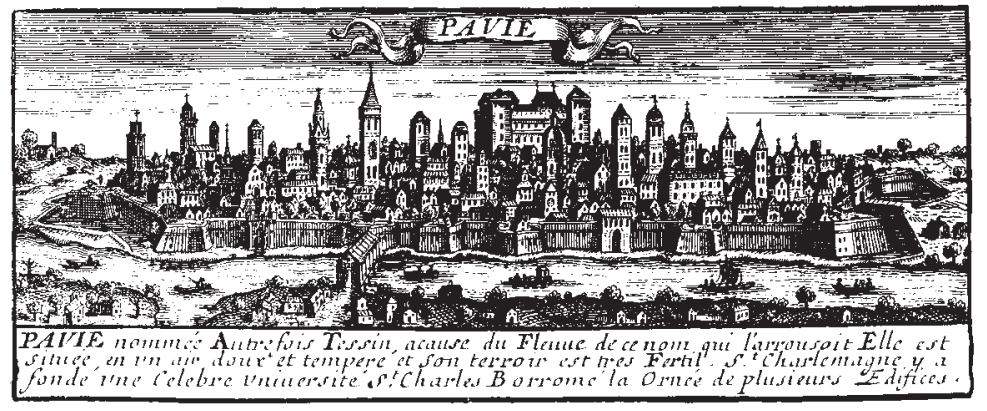

